\title{
SIALOENDOSCOPIC TREATMENT OF PAROTID GLAND DISEASES
}

\author{
Tsvetan Tonchev', Plamen Nedev², Yavor Enchev², Mario Milkov ${ }^{3}$ \\ ${ }^{1}$ Department of Oral and Maxillofacial Surgery and Special Imaging, \\ Faculty of Dental Medicine, Medical University of Varna, Bulgaria \\ ${ }^{2}$ Department of Neurosurgery and ENT, Faculty of Medicine, \\ Medical University of Varna, Bulgaria \\ ${ }^{3}$ Department of Prosthetic Dentistry and Orthodontics, Faculty of Dental Medicine, \\ Medical University of Varna, Bulgaria
}

\begin{abstract}
In the present survey, the emergence of parotid gland endoscopy or sialoendoscopy as well as the most recent achievements of this minimally invasive technique for safe and effective treatment of salivary gland diseases are discussed. The results from some meta-analyses in this interdisciplinary field are briefly presented. The clinical applications of interventional sialoendoscopy in patients with chronic parotitis, in adults and children as well as with salivary gland stones are briefly presented.
\end{abstract}

Keywords: interventional sialoendoscopy, chronic parotitis, juvenile recurrent parotitis, sialolithiasis, meta-analyses

\section{GENERAL CHARACTERIS- TICS OF INTERVENTIONAL SIALOENDOSCOPY}

Parotid gland endoscopy or sialoendoscopy is a minimally invasive technique for safe and effective treatment of salivary gland inflamamatory diseases, obstructions, strictures and salivary stones. During sialoendoscopy, a small camera is placed into the parotid gland through the salivary ducts that empty into the mouth. Depending on the obstruction, sialoendoscopy can be carried out either under local anesthesia in an outpatient office, or in the hospital op-

\footnotetext{
Address for correspondence:

Tsvetan Tonchev

Faculty of Dental Medicine,

Medical University of Varna

84 Tzar Osvoboditel Blvd.

9000 Varna, Bulgaria

e-mail:mfstonchev@mu-varna.bg
}

Received: November 3, 2015

Accepted: December 1, 2015 erating room under general anesthesia. The salivary duct opening should be either dilated or incised prior to endoscope introduction. Then saline is used to dilate the salivary duct and its branching. The endoscope is introduced into the gland through its natural orifice in the mouth or by a making a small incision in the duct opening. After endoscope introduction, the internal anatomy is examined for subsequent treatment of a specific disease entity.

The ability to perform this technique results from the development of miniaturized endoscopic imaging tools. Nowadays, most sialoendoscopes are of semirigid type. They allow for visualization of the lesions as the stiffness permits manipulation and navigation of the internal salivary anatomy. Multiple types of microinstruments are available such as grasping forceps, biopsy forceps, drills, needles, laser fibers, and lithotripters.

Nowadays treatment by invasive endoscopy, intracorporeal lithotripsy, and extracorporeal lithotripsy develops worldwide as an alternative to open surgical procedures. 
When the stone diameter is $\leq 5 \mathrm{~mm}$, the sialolith can be removed by an endoscopic technique, particularly when located above the muscles that comprise mouth floor. The following techniques are used to remove the salivary gland stones: grasping technique; using a small wire basket retrieval system; mechanical fragmentation and laser fragmentation.

When the stone diameter is $>5 \mathrm{~mm}$, a twofold, endoscopically assisted approach is used. The stone is localized, dissected and removed in an intraoral approach. After sialolith removal, a sialastic stent is inserted into the duct for two to four weeks enabling the healing process of the oral region and the restoration of the normal gland function. This prevents scar formation which can develop overlying the ductal opening into the mouth.

Sialoendoscopy is introduced in the early 1990s as a minimally invasive alternative to standard methods for treatment of inflammatory and obstructive parotid gland disease in adult patients (3). Recent advances in instrumentation allow its adaptation to the smaller salivary ductal anatomy in the pediatric population, too. In 1990, R. Konigsberger et al. and P. Gundlach et al. separately perform sialoendoscopy by introducing the endoscope into the major salivary glands. In France, P. Katz (1990) introduces the fiberscope for the examination of the salivary glands. Later on, P. Katz (1991) applies a 0.8-mm flexible endoscope to treat salivary gland stones. R. Königsberger et al. (1993) introduce a new minimally invasive endoscopically-controlled electrohydraulic shock wave lithotripsy for salivary gland stones. By using rigid miniendoscope, O. Nahlieli et al. (1994) treat eight cases of sialolithiasis causing major salivary gland obstructions for the first time with salivary gland endoscopy, a new technique which combines endoscopy and treatment. Between 1988 and 2002, a total of 668 duct endoscopies with instrumentation and/ or intracorporeal laser lithotripsy or electromagnetic extracorporeal shock wave lithotripsy for major salivary lithiasis were performed in France (16). Lithotripsy completely destroys the stones in $63 \%$ of the lithotriptor cases. In 35\% of these procedures, there is stone fragmentation with spontaneous expulsion or ancillary endoscopic removal. There are no major complications such as nerve or tooth damage.

\section{META-ANALYSES OF PUBLI- CATIONS ON THERAPEUTIC SIALOENDOSCOPY}

A meta-analysis of 11 English-language articles retrieved from MEDLINE, EMBASE and the Cochrane library shows that the success rate of sialendoscopy combined with minor surgical removal of parotid sialoliths ranges from 69 to $100 \%$ (13).

The results of a systematic review of publications retrieved from MEDLINE, EMBASE, Web of Knowledge, the Cochrane Library, and the National Health Service Centre for Reviews and Dissemination reveals a weighted pooled proportion of success rates of the obstruction's resolution of $76 \%$ (95\% CI $=71-82$ ) for 40 studies involving 2654 patients undergoing sialoendoscopy alone, and of $91 \%$ (95\% CI=88-94) for 23 studies and 1480 procedures made with sialoendoscopy and a combined surgical approach (2).

A systematic review and meta-analysis of seven prospective or retrospective studies of pediatric patients treated with interventional sialendoscopy for the management of juvenile recurrent parotitis retrieved from MEDLINE, EMBASE, the Cochrane library, and Google Scholar suggests that sialendoscopy is an effective and safe therapeutic method for appropriate patients (32).

\section{THERAPEUTIC SIALOENDOSCOPY IN CHRONIC PAROTITIS}

Between November 2004 and June 2011, 36 patients with juvenile recurrent parotitis were treated (34). Of them, 15 underwent salivary gland endoscopy with cortisone irrigation and 21 ones were managed with antibiotic therapy alone. There was a significant reduction of recurrent episodes and pain intensity following therapy in both groups.

R. Semensohn et al. (2015) performed diagnostic and therapeutic sialendoscopy in nine children with juvenile recurrent parotitis and three children with chronic submandibular sialadenitis. They detected ductal stricture in eight cases, thick intraductal mucus in six cases and ductal calculus in one case. The average follow-up was 16.5 months (range: 1-49 months), and during that time two patients had a recurrence (16,67\% of the cases). One patient had a repeated recurrence which resolved after salvage pa- 
Tsvetan Tonchev, Plamen Nedev, Yavor Enchev et al.

rotidectomy and another patient had one isolated recurrence which resolved with antibiotics.

T. E. Heineman et al. (2015) examined 19 patients with idiopathic chronic parotitis during a median follow-up of five months. Computed tomography imaging had a sensitivity and specificity of 80.0 and $71.4 \%$, respectively, for predicting abnormal findings on sialendoscopy, while magnetic resonance imaging had $100 \%$ accuracy in a small set of patients. There was a symptomatic improvement after treatment in 11 out of 12 glands with noticeable pathology present on preoperative imaging or sialendoscopy, while three out of seven glands without such a pathology experienced symptomatic improvement $(\mathrm{p}=0.038)$.

Usage of the therapeutic salendoscopy in idiopathic chronic parotitis improves pain and swelling with a higher frequency of success in case of abnormalities noted on endoscopy.

Interventional sialendoscopy under local anesthesia was carried out in 12 patients with chronic radioiodine-induced sialadenitis following the treatment of thyroid disease (37). The results from the examinations using visual analogue scale and salivary gland scintigraphy demonstrated a statistically significant improvement after the operation $(\mathrm{p}<0.05)$.

Usage of interventional therapeutic sialendoscopy in 50 children aged 2-16 years with juvenile recurrent parotitis between 2003 and 2012 demonstrated satisfactory results (1). Seven out of 43 children with unilateral parotitis underwent additional sialendoscopy because of recurrence.

In three children at a mean age of nine years (range 6-11 years) with juvenile recurrent parotitis who failed conservative medical management, interventional sialendoscopy consisted of serial Stenson's duct dilation, ductal system endoscopy and saline irrigation followed by instillation of triamcinolone acetate (7). Technical success rate was $100 \%$. During the last follow-up, there were neither new juvenile recurrent parotitis episodes, nor any major postoperative complications. There is a learning curve with sialendoscope use. Pediatric sialendoscopy is more challenging and should be incorporated into one's practice after developing a comfort level and an initial experience of sialendoscopy in an adult population. As this is not always feasible in exclusively pedi- atric practices, training in sialendoscopy and collaboration with someone experienced in sialendoscopy helps bridge these difficulties (7).

Between January 1, 2003 and November 30, 2008 , pediatric sialendoscopy under general anesthesia was performed on the parotid gland in 23 patients mainly because of recurrent salivary gland swelling (23). Thirty-two procedures were carried out endoscopically, whereas a combined intervention was necessary for three patients only.

Therapeutic sialendoscopy with dilation and irrigation of the ductal system of 23 parotid glands in nine female and two male patients was performed for ${ }^{131}$ I sialadenitis after failing medical management (31). Most patients reported improvement of symptoms after a single procedure. At a mean follow-up of 18 months, there was a complete symptom resolution with sustained benefit in six patients while a partial improvement of symptoms with some persistent intermittent episodes of pain or swelling was observed in other four patients.

In a single tertiary-care pediatric otolaryngology practice, therapeutic sialendoscopy was carried out in three children with bilateral and two ones with unilateral parotid gland inflammation (12). There were no postoperative complications. In three children, there was no postoperative recurrence but a decreased frequency of recurrence was noted in two children. Operative findings from 10 parotid glands showed fibrinous debris in seven as well as mucoid debris, purulent debris and duct stenosis in one patient each. There were no parotid gland stones at all.

Before sialoendoscopy, 31 patients with chronic obstructive parotitis underwent ultrasonography and salivary gland scintigraphy examinations (38). Thirty patients (or 44 parotid glands) successfully underwent interventional sialendoscopy under local anesthesia while one patient (or one parotid gland) received general anesthesia. Preoperatively, the mean visual analogue scale score was six and six months postoperatively it was 4.9 that is statistically significantly lower $(\mathrm{p}<0.05)$.

Among 50 children at a mean age of 7.5 years, juvenile recurrent parotitis was diagnosed in 40 and sialolithiasis was detected in the rest ten ones (33). Sialoendoscopy was carried out in 15 children from the first group. These patients had significantly high- 
er costs of care during the period of observation than those who are not operated on.

The analysis of the therapeutic effect of an intraductal sialoendoscopic application of corticosteroids on the clinical course of nine children with chronic recurrent juvenile parotitis during an average follow-up period of 15 months revealed that there were no side effects associated with the sialendoscopy (25). All symptoms completely resolved in eight children. One child still showed slight parotid swellings without any need for antibiotics.

\section{THERAPEUTIC SIALOENDOSCOPY IN SIALOLITHIASIS}

According to the interdisciplinarily developed German S2k AWMF guideline for the treatment of obstructive sialadenitis, therapeutic options such as interventional sialendoscopy and extracorporeal shock-wave lithotripsy are available in combination with marsupialization or incision of the duct (36).

The results from a retrospective review of 112 consecutive patients with obstructive salivary disorders indicated that anteriorly located parotid gland stones are more accessible for endoscopic management, whereas posterior ones require combined approaches for management by a transfacial approach for their removal (17).

In six patients with obstructive sialadenitis caused by sialolithiasis surgery using a purely sialendoscopic technique was not done because either of the stone size, or of a tight distal stricture obstructing the passage of endoscopic stone removal, therefore a combined therapeutic approach was used (18). Endoscope application enabled further exploration of the remaining duct thus allowing for the removal of further sialoliths and subsequent duct reconstruction.

During a retrospective study from 2004-2009 in Eastern Denmark, a total of 53 parotid endoscopies for treatment of non-neoplastic obstruction were performed (5). The indications for sialoendoscopy were sialolithiasis, stenosis, recurrent swelling and recurrent infections. There was an overall success rate of $62 \%$ in interventional endoscopies.

The analysis of patient's tolerance of sialendoscopy of the parotid gland indicates that most patients consider the procedure to be tolerable (22). The indications for conducting sialendoscopy under general anesthesia are procedures of greater invasiveness and complex situations with multiple sialolithiases, difficult anatomic preconditions, or a very long expected operation time.

The sialendoscopic thulium-YAG fiber laser was used in a pulsed mode with an average power output of 2-8 W to fragment and facilitate extraction of parotid lithiasis in 40 patients (6). Stone size was preoperatively evaluated by ultrasound. The mean size was $5.7 \mathrm{~mm}$ and varied between 2 and $18 \mathrm{~mm}$. The mean energy per procedure was 1,450 J (range: $1,400-1,800 \mathrm{~J})$.

In a comprehensive review, the current literature devoted to the therapeutic outcomes after the application of sialendoscopy in juvenile recurrent parotitis patients was discussed (4).

Within a prospective observational study in New Zealand between June 2010 and June 2012, I. Ianovski et al. (2014) used the Glasgow Benefit Inventory questionnaire to assess the patient-perceived outcome after sialendoscopy for obstructive salivary gland diseases. Fifty-four patients underwent a total of 66 sialendoscopic procedures involving 44 parotid and 22 submandibular glands. There was a complete symptom resolution in 54 procedures (in $81,82 \%$ of the cases). Sialolith removal was successful in $67 \%$ of the sialolithiasis cases, with postsialendoscopy symptom resolution in $86 \%$ of the cases. The symptoms resolved in $81 \%$ of the patients with ductal stenosis. The overall mean Glasgow Benefit Inventory score was +31 and compared very favourably with other otolaryngological procedures.

Ten consecutive patients with parotid gland sialolithiasis were successfully treated using the combined endoscopic and transcutaneous approach. They had previously undergone a sialendoscopy under local anesthesia and presented with large, immobile salivary stones in the deeper salivary duct system (26). In $60 \%$ of the cases, a temporary stenting of the salivary duct was performed. All the patients showed good clinical results with restored drainage of the salivary duct system and preserved parotid gland function.

In a retrospective study covering the period between 2010 and 2012, O. Nahlieli (2015) established a total of 17 postopetative complications associated with the application of sialendoscopy (intraduct- 
Tsvetan Tonchev, Plamen Nedev, Yavor Enchev et al.

al endoscopy or endoscopy-assisted extraductal approach) among 498 consecutive patients with salivary gland stones located in the parotid, submandibular, and sublingual glands (in 3,41\% of the cases). The most common complications weree strictures, ranulas, and lingual nerve paresthesias.

Between 2003 and 2010, 55 consecutive patients underwent endoscopically assisted surgical removal of parotid stones from 57 glands as minimally invasive radiological or endoscopic techniques alone are inefficient (30). During a median follow-up of 3.1 years, 28 glands $(70 \%)$ were symptomless while 11 ones $(28 \%)$ of the cases were much improved but caused mild or occasional residual symptoms. One patient required postoperative lithotripsy and basket retrieval of a retained stone and then was symptom free.

Endoscope-assisted partial-superficial parotidectomy through a concealed postauricular skin incision was successfully performed in 18 cases of benign tumor located in the superficial parotid gland lobe (10). This approach provides safe dissection of the facial nerve and exposed working space. The duration of the procedure was 90 to $120 \mathrm{~min}$.

In eight patients with large and impacted intraductal parotid salivary gland stones with an average diameter of $7.6 \mathrm{~mm}$ (range 7.0-10.2 $\mathrm{mm}$ ), a combined endoscopic and transcutaneous technique was successfully used (29). The stone was approached endoscopically, a skin flap was raised over or a small incision was made through the illuminated area, and then the stone was removed by an external route with minimal morbidity rate. Six patients were symptom free after the intervention and superficial parotidectomy was performed in one patient.

Between 2003 and 2008, 206 out of 221 parotid gland stones were treated in a tertiary referral academic medical centre by salivary gland endoscopy and other gland-preserving techniques such as extracorporeal shockwave lithotripsy, transoral stone removal, and combinations of these methods (39). The parotid gland stones were removed by salivary gland endoscopy in $22 \%$, by combined salivary gland endoscopy and incisional technique in $26 \%$, or by extracorporeal shockwave lithotripsy in 52\% of the cases, with long-term success rates of $98 \%, 89 \%$, and
$79 \%$, respectively. Only eight patients $3.88 \%$ of the cases) eventually required parotidectomy.

Within a prospective study between December 2008 and November 2011, 185 sialendoscopies were performed in 162 patients in a tertiary university centre (21). Among 29 patients with parotid sialolithiasis, endoscopy was the definite treatment in 15 cases, extracorporeal shock-wave lithotripsy was necessary in nine cases and a combined approach was performed in 5 cases who failed the other two methods. Sialoendoscopy was the method of choice with a high rate of success and gland preservation in small and medium stones. The combined transcutaneous and endoscopic approach was indicated for large stones, for complications after and contraindications in applying the minimally invasive procedures.

Minimally invasive surgery of parotid gland sialolithiasis using sialoendoscopy was performed in five patients without any salivary gland removal (24). Stone size and shape are significant predictors for successful endoscopic stone removal.

During the operative treatment of strictures and adhesions, the surgeon establishes the exact location of the obstruction using a sialogram and then applies the endoscopic method. The first step is anesthetizing and laving the duct with $2 \%$ lidocaine and saline. If there is no improvement, the surgeon inserts a dilation balloon, which can be inflated up to $3 \mathrm{~mm}$. The pressure created by the inflation enables to dilate most strictures. Another technique is to expand the stricture region with grasping forceps used as a dilator.

\section{REFERENCES}

1. Ardekian L, Klein H, Al Abri R, Marchal F. Sialendoscopy for the diagnosis and treatment of juvenile recurrent parotitis. Rev Stomatol Chir Maxillofac Chir Orale. 2014;115(1):17-21.

2. Atienza G, López-Cedrún JL. Management of obstructive salivary disorders by sialendoscopy: a systematic review. Br J Oral Maxillofac Surg. 2015;53(6):507-519.

3. Bruch JM, Setlur J. Pediatric sialendoscopy. Adv Otorhinolaryngol. 2012;73:149-152.

4. Canzi P, Occhini A, Pagella F, Marchal F, Benazzo M. Sialendoscopy in juvenile recurrent parotitis: a review of the literature. Acta Otorhinolaryngol Ital. 2013;33(6):367-373. 
5. Danquart J, Wagner N, Arndal H, Homøe P. Sialoendoscopy in the salivary glands. Dan Med Bull. 2011;58(2):A4232.

6. Durbec M, Dinkel E, Vigier S, Disant F, Marchal F, Faure F. Thulium-YAG laser sialendoscopy for parotid and submandibular sialolithiasis. Lasers Surg Med. 2012;44(10):783-786.

7. Gary C, Kluka EA, Schaitkin B, Walvekar RR. Interventional sialendoscopy for treatment of juvenile recurrent parotitis. J Indian Assoc Pediatr Surg. 2011;16(4):132-136.

8. Gundlach P, Scherer H, Hopf J, Leege N, Müller G, Hirst L, Scholz C. Endoscopic-controlled laser lithotripsy of salivary calculi. In vitro studies and initial clinical use. HNO. 1990;38(7):247-250 (in German).

9. Heineman TE, Kacker A, Kutler DI. Idiopathic chronic parotitis: imaging findings and sialendoscopic response. ORL J Otorhinolaryngol Relat Spec. 2015;77(5):302-309.

10. Huang X, Sun W, Liu X, Liu W, Guan Z, Xu Y, Zheng Y. Endoscope-assisted partial-superficial parotidectomy through a concealed postauricular skin incision. Surg Endosc. 2009;23(7):1614-1619.

11. Ianovski I, Morton RP, Ahmad Z. Patient-perceived outcome after sialendoscopy using the Glasgow Benefit Inventory. Laryngoscope. 2014;124(4):869-874.

12. Jabbour N, Tibesar R, Lander T, Sidman J. Sialendoscopy in children. Int J Pediatr Otorhinolaryngol. 2010;74(4):347-350.

13. Jadu FM, Jan AM. A meta-analysis of the efficacy and safety of managing parotid and submandibular sialoliths using sialendoscopy assisted surgery. Saudi Med J. 2014;35(10):1188-1194.

14. Katz P. New method of examination of the salivary glands: the fiberscope. Inf Dent. 1990;72(10):785786 (in French).

15. Katz P. Endoscopy of the salivary glands. Ann Radiol (Paris). 1991;34(1-2):110-113 (in French).

16. Katz P. Nouvelles techniques de traitements des lithiases salivaires : sialoendoscopie et lithotripsie extra-corporelle. Ann Otolaryngol Chir Cervicofac. 2004;121(3):123-132.

17. Kiringoda R, Eisele DW, Chang JL. A comparison of parotid imaging characteristics and sialendoscopic findings in obstructive salivary disorders. Laryngoscope. 2014;124(12):2696-2701.
18. Klein H, Ardekian L. The treatment of large sialoliths by sialendoscopic combined approach. J Oral Maxillofac Surg. 2014;72(4):737-743.

19. Königsberger R, Feyh J, Goetz A, Schilling V, Kastenbauer E. Endoscopic controlled laser lithotripsy in the treatment of sialolithiasis. Laryngorhinootologie. 1990;69(6):322-323 (in German).

20. Königsberger R, Feyh J, Goetz A, Kastenbauer E. Endoscopically-controlled electrohydraulic intracorporeal shock wave lithotripsy (EISL) of salivary stones. J Otolaryngol. 1993;22(1):12-13.

21. Kopeć T, Szyfter W, Wierzbicka M. Sialoendoscopy and combined approach for the management of salivary gland stones. Eur Arch Otorhinolaryngol. 2013;270(1):219-223.

22. Luers JC, Stenner M, Schinke M, Helmstaedter $\mathrm{V}$, Beutner D. Tolerability of sialendoscopy under local anesthesia. Ann Otol Rhinol Laryngol. 2012;121(4):269-274.

23. Martins-Carvalho C, Plouin-Gaudon I, Quenin S, Lesniak J, Froehlich P, Marchal F, Faure F. Pediatric sialendoscopy: a 5-year experience at a single institution. Arch Otolaryngol Head Neck Surg. 2010;136(1):33-36.

24. Matsunobu T, Kurioka T, Miyagawa Y, Araki K, Tamura A, Niwa K, Tomifuji M, Yamashita T, Shiotani A. Minimally invasive surgery of sialolithiasis using sialendoscopy. Auris Nasus Larynx. 2014;41(6):528-531.

25. Mikolajczak S, Meyer MF, Beutner D, Luers JC. Treatment of chronic recurrent juvenile parotitis using sialendoscopy. Acta Otolaryngol. 2014;134(5):531-535.

26. Mikolajczak S, Bremke M, Beutner D, Luers JC. Combined endoscopic and transcutaneous approach for immobile parotid stones. Acta Otolaryngol. 2015;135(1):85-89.

27. Nahlieli O, Neder A, Baruchin AM. Salivary gland endoscopy: a new technique for diagnosis and treatment of sialolithiasis. J Oral Maxillofac Surg. 1994;52(12):1240-1242.

28. Nahlieli O. Complications of sialendoscopy: personal experience, literature analysis, and suggestions. J Oral Maxillofac Surg. 2015;73(1):75-80.

29. Numminen J, Sillanpää S, Virtanen J, Sipilä M, Rautiainen M. Retrospective analysis of a combined endoscopic and transcutaneous technique for the management of parotid salivary 
gland stones. ORL J Otorhinolaryngol Relat Spec. 2014;76(5):282-287.

30. Overton A, Combes J, McGurk M. Outcome after endoscopically assisted surgical retrieval of symptomatic parotid stones. Int J Oral Maxillofac Surg. 2012;41(2):248-251.

31. Prendes BL, Orloff LA, Eisele DW. Therapeutic sialendoscopy for the management of radioiodine sialadenitis. Arch Otolaryngol Head Neck Surg. 2012;138(1):15-19.

32. Ramakrishna J, Strychowsky J, Gupta M, Sommer DD. Sialendoscopy for the management of juvenile recurrent parotitis: a systematic review and metaanalysis. Laryngoscope. 2015;125(6):1472-1479.

33. Rosbe KW, Milev D, Chang JL. Effectiveness and costs of sialendoscopy in pediatric patients with salivary gland disorders. Laryngoscope. 2015 May 22. doi: 10.1002/lary.25384.

34. Schneider H, Koch M, Künzel J, Gillespie MB, Grundtner P, Iro H, Zenk J. Juvenile recurrent parotitis: a retrospective comparison of sialendoscopy versus conservative therapy. Laryngoscope. 2014;124(2):451-455.

35. Semensohn R, Spektor Z, Kay DJ, Archilla AS, Mandell DL. Pediatric sialendoscopy: initial experience in a pediatric otolaryngology group practice. Laryngoscope. 2015;125(2):480-484.

36. Vogl TJ, Al-Nawas B, Beutner D, Geisthoff U, Gutinas-Lichius O, Naujoks C, Reich R, Schröder U, Sproll C, Teymoortash A, Ußmüller J, Wittekindt C, et al. Updated S2K AWMF guideline for the diagnosis and follow-up of obstructive sialadenitis - relevance for radiologic imaging. Röfo. 2014;186(9):843-846.

37. Wu CB, Xi H, Zhou Q, Zhang LM. Sialendoscopyassisted treatment for radioiodine-induced sialadenitis. J Oral Maxillofac Surg. 2015;73(3):475-481.

38. Wu CB, Xue L, Zhang B, Sun NN, Zhou Q. Sialendoscopy-assisted treatment for chronic obstructive parotitis - our treatment strategy with 31 patients. J Oral Maxillofac Surg. 2015a;73(8):1524-1531.

39. Zenk J, Koch M, Klintworth N, König B, Konz K, Gillespie MB, Iro H. Sialendoscopy in the diagnosis and treatment of sialolithiasis: a study on more than 1000 patients. Otolaryngol Head Neck Surg. 2012;147(5):858-863. 